\title{
The Effect of Eliminating Intermediate Severity Drug-Drug Interaction Alerts on Overall Medication Alert Burden and Acceptance Rate
}

\author{
Amy M. Knight ${ }^{1}$ Joyce Maygers ${ }^{2}$ Kimberly A. Foltz \\ Daniel J. Brotman 6 \\ ${ }^{1}$ Division of Hospital Medicine, Department of Medicine, Johns Hopkins \\ University School of Medicine, Baltimore, Maryland, United States \\ 2 Department of Care Management, Johns Hopkins Bayview Medical \\ Center, Baltimore, Maryland, United States \\ 3 Division of Clinical Informatics, Department of Information Services, Johns \\ Hopkins Bayview Medical Center, Baltimore, Maryland, United States \\ ${ }^{4}$ American Pharmacists Association, Washington, District of \\ Columbia, United States \\ ${ }^{5}$ Department of Epidemiology, Johns Hopkins Bloomberg School of \\ Public Health, Baltimore, Maryland, United States \\ ${ }^{6}$ Division of General Internal Medicine, Department of Medicine, \\ Johns Hopkins University School of Medicine, Baltimore, \\ Maryland, United States
}

Appl Clin Inform 2019;10:927-934.

\author{
Address for correspondence Amy M. Knight, MD, Johns Hopkins \\ Bayview Medical Center, 5200 Eastern Avenue, MFL 2E Division of \\ Hospital Medicine, Baltimore, Maryland 21224-2780, United States \\ (e-mail: aknight@jhmi.edu).
}

\section{Abstract}

Keywords

- clinical decision support

- medication alerts

- high-alert medications

- computerized physician order entry

- alert fatigue
Objective This study aimed to determine the effects of reducing the number of drugdrug interaction (DDI) alerts in an order entry system.

Methods Retrospective pre-post analysis at an urban medical center of the rates of medication alerts and alert acceptance during a 5-month period before and 5-month period after the threshold for firing DDI alerts was changed from "intermediate" to "severe." To ensure that we could determine varying response to each alert type, we took an in-depth look at orders generating single alerts.

Results Before the intervention, 241,915 medication orders were placed, of which $25.6 \%$ generated one or more medication alerts; $5.3 \%$ of the alerts were accepted. During the postintervention period, 245,757 medication orders were placed of which $16.0 \%$ generated one or more medication alerts, a $37.5 \%$ relative decrease in alert rate (95\% confidence interval [CI]: -38.4 to $-36.8 \%$ ), but only a $9.6 \%$ absolute decrease (95\% Cl: -9.4 to $-9.9 \%$ ). $7.4 \%$ of orders generating alerts were accepted postintervention, a $39.6 \%$ relative increase in acceptance rate (95\% Cl: $33.2-47.2 \%)$, but only a $2.1 \%$ absolute increase $(95 \% \mathrm{Cl}: 1.8-2.4 \%)$. When only orders generating a single medication alert were considered, there was a $69.1 \%$ relative decrease in the number of orders generating DDI alerts, and an $85.7 \%$ relative increase in the acceptance rate (95\% Cl: $58.6-126.2 \%)$, though only a $1.8 \%$ absolute increase (95\% Cl: $1.3-2.3 \%$ ).

Conclusion Eliminating intermediate severity DDI alerts resulted in a statistically significant decrease in alert burden and increase in the rate of medication alert acceptance, but alert acceptance remained low overall. received

March 12, 2019

accepted after revision

October 7, 2019 (c) 2019 Georg Thieme Verlag KG Stuttgart · New York
DOI https://doi.org/ $10.1055 / \mathrm{s}-0039-3400447$. ISSN 1869-0327. 


\section{Background and Significance}

Computerized clinical decision support is intended to provide information when making decisions that will promote patient care that is safe, complete, and supported by guidelines and evidence. ${ }^{1,2}$ Decision support has been shown to improve some health care processes ${ }^{3,4}$ however, clinicians now encounter multiple alerts each day, ${ }^{5}$ many of them intrusive or of limited clinical value. ${ }^{6}$ Clinicians can receive so many interruptive alerts that they develop "alert fatigue," and become desensitized to them. ${ }^{7-10}$ The problem can be particularly severe with alerts generated for medication orders. ${ }^{11}$ Clinicians with alert fatigue override medication alerts at a high rate, ${ }^{11}$ potentially ignoring clinically important alerts in the process. ${ }^{12,13}$ Negative patient outcomes can result. ${ }^{14-16}$

While it seems intuitive that the fewer alerts there are, the more effective they will be, there is limited evidence for this. Our hospital's medication safety committee obtained data showing that medication alerts were infrequently accepted at our hospital. ${ }^{17}$ They also learned that providers at other institutions encountered many fewer medication alerts. ${ }^{18,19}$ The committee subsequently requested a reduction in the alert burden in our order entry system. While drug-drug interaction (DDI) and drug-duplicate medication alerts appeared to both be firing excessively, DDI alerts appeared to be accepted at an especially low rate. The group therefore recommended first increasing the threshold for generating DDI alerts from "intermediate" to "severe," that is, eliminating intermediate severity DDI alerts. We were not aware of prior research looking at the effects of turning off an entire class of alerts. We therefore designed a study examining the rates of medication alert acceptance following this change.

\section{Methods}

\section{Setting and Caregivers}

Johns Hopkins Bayview Medical Center (JHBMC) is a 400-bed academic medical center at Baltimore in Maryland. Providers in this study included residents and fellows who rotate to both JHBMC and Johns Hopkins Hospital (JHH), attending physicians (including both teaching attendings and attending hospitalists), and advanced practice providers (APPs; including nurse practitioners, nurse midwives, nurse anesthetists, and physician assistants) from all adult departments. Nurses, pharmacists, respiratory therapists, and medical students are able to place orders, with later cosignature by an authorized prescriber, and were therefore included in the study as well.

\section{Baseline Order Entry Configuration}

Between 2003 and 2004, JHBMC implemented a commercial electronic medical record system (EMR; Meditech Corporation, Westwood, Massachusetts, United States). The EMR's features included computerized provider order entry, provider and nurse documentation, and resulting for laboratory and imaging tests. When medication orders were placed using the EMR, they could generate drug-duplicate, drug-allergy, adverse reaction, DDI, and drug-dose alerts. The alerts "popped up" in a new window when attempting to sign all orders from an ordering session, interrupting the provider's workflow, and required a response before the provider could continue. When more than one drug-duplicate, drug-allergy, adverse reaction, or DDI alert were generated for a particular medication, all appeared in the same interruptive alert in identical font and color, as shown in - Fig. 1. Providers could choose to disregard the alerts by clicking on an "Override"

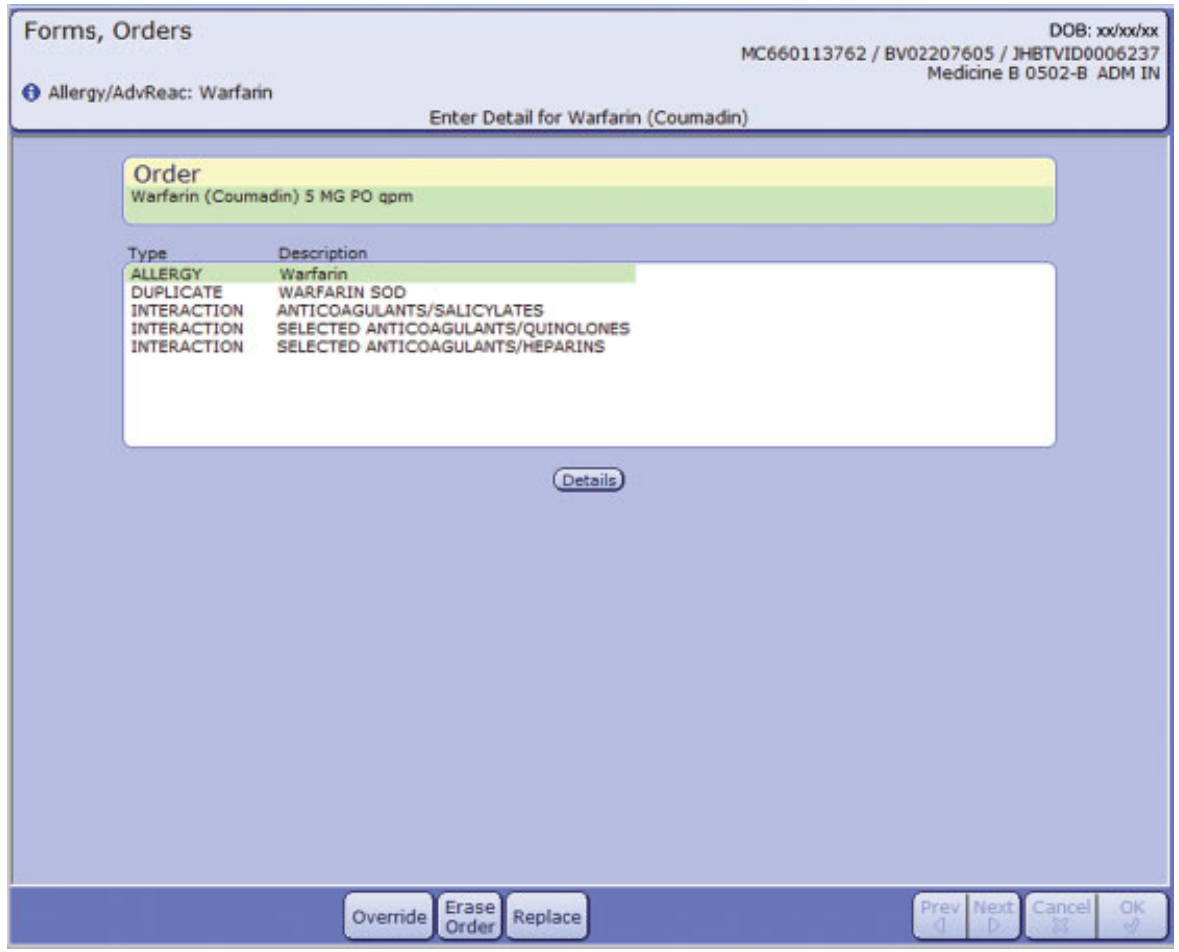

Fig. 1 Typical medication alert (used with permission from Meditech Corporation). 


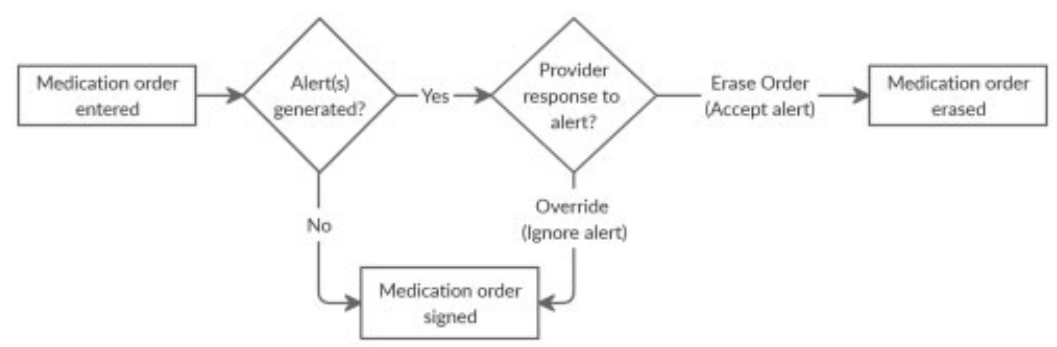

Fig. 2 Workflow for responding to medication alerts.

button at the bottom of the window that closed the window and allowed the new order to be placed or accept the alerts by clicking on an "Erase Order" button. This workflow is shown in -Fig. 2.

Drug-duplicate medication alerts were generated when a medication was ordered for which the patient was already prescribed or which had been administered in the last 24 hours; no exceptions were allowed for medications commonly reordered more than once a day. Drug-duplicate medication alerts were only generated for the same medication, and not for other medications from the same class. Drug-allergy or adverse reaction alerts were generated when a medication was ordered for a patient who had an allergy or adverse reaction (e.g., nausea and headache) documented in the EMR for that medication or medication class.

Medication alerts utilized a drug information database licensed from First DataBank (San Francisco, California, United States). First DataBank is one of the main suppliers of drug information databases in the United States, which can be integrated with EMRs to inform decisions when ordering, verifying and documenting administration of medications. First DataBank classifies potential DDIs as "contraindicated," "severe," “intermediate," and "mild." DDIs classified as "contraindicated" by First DataBank were grouped with those in the "severe" category in our EMR, resulting in three functional categories, mild, intermediate, and severe. Prior to the intervention, JHBMC's version of the EMR was configured so that providers were alerted to potential "severe" (including "contraindicated") and "intermediate" DDI but not those classified as "mild." No other customizations had been made to the database. DDI alerts showed the category of the ordered medication followed by the category of the medication for which there was a potential DDI. A "Details" button could be selected to learn specifically which medications were involved and the severity and nature of the potential DDIs identified. The system did not prompt users to discontinue the interacting medications that the patient was already on, or track any subsequent changes to them. The DDI alerts were only for other medications, not for food or laboratory results.

Drug-dose alerts appeared on a separate screen and are not addressed in this manuscript.

\section{Intervention}

As a quality-improvement initiative, JHBMC's Medication Error Reduction Improvement Team (MERIT) reviewed the medications generating alerts and proposed that the system be changed so that providers would only see "severe" DDI alerts and not be presented with the "intermediate" ones any more. This change was intended to eliminate approximately $75 \%$ of all DDI alerts, with a primary objective of increasing the acceptance rate for the remaining DDI alerts, and a secondary objective of increasing the acceptance rate for other types of medication alerts. The change was approved by the Pharmacy and Therapeutics Committee, and implemented on January 22, 2014. Providers were informed about the change through an e-mail announcement.

\section{Data Collection}

We conducted a retrospective pre-post audit of all medications ordered, and all medication alerts generated and displayed to providers, for all hospitalized adults who had medications ordered for 5 months before (August 22, 2013-January 21, 2014) and 5 months after (January 23, 2014-June 22, 2014) the change was made. It was not possible to determine if providers who accepted an alert, by erasing an order, subsequently reordered the medication. We collected descriptive data about patients and providers using administrative databases.

There was wide variation in the number of alerts generated per medication order. For example, if warfarin was ordered for a patient who was already on warfarin, a drug-duplicate alert would appear. However, if warfarin was ordered for a patient who was already on warfarin, but also allergic to warfarin, and taking one or more medications that interfered with warfarin, then drug-duplicate, drug-allergy, and DDI alerts would all appear on the same screen, as shown in -Fig. 1. If the user in the second case responded by clicking on "Erase Order," accepting the alert, it would be impossible to ascertain if they were responding primarily to the drug-allergy, drugduplicate, or DDI alert. Therefore, to ensure that we could accurately determine different responses to each alert type, we separately analyzed medication orders that only generated single alerts. For each single alert, we obtained patient age, gender, hospital unit, event date, ordered medication, ordering caregiver, alert type, and caregivers' responses to the alert ("Override" alert or "Erase Order" [i.e., accept the alert]). There were very few orders placed by pharmacists, respiratory therapists, and medical students, and therefore these were grouped in an "Other Caregiver" category. At JHBMC, fellows can moonlight as attending physicians and therefore they were categorized with attendings. Hospital units were grouped according to acuity of care, depending on whether they served intensive care unit (ICU) or more stable "floor" patients. 
Medications that were available in more than one form included the route of administration in their name, and, from this, they were categorized as parenteral or nonparenteral. For descriptive purposes, all nonparenteral forms of a given medication were grouped together as one medication, for example, sustained release of morphine and morphine elixir were classified as a single medication, "nonparenteral morphine"; similarly, parenteral forms of the medications were grouped together. Medications were further categorized according to whether or not they were on the Institute for Safe Medication Practice's list of high-alert medications (ISMP list). ${ }^{20}$

\section{Analysis}

Descriptive statistics were used for the medication orders generating any number of alerts. Alerts were dichotomously categorized according to whether they were overridden or accepted. For the orders, generating only single alerts, Student's $t$-test or Wilcoxon's rank-sum test was used to compare means or medians of continuous variables for the two groups, and Chisquare tests were used to compare the distributions of proportions of categorical variables. Multivariable Poisson regression was subsequently performed to calculate rate ratios for overriding versus accepting alerts, after adjusting for patient age, caregiver type, parenteral versus nonparenteral medication, and whether or not the medication is on the ISMP list of highalert medications that were the factors found to be significantly predictive of failure to accept alerts in our prior study. ${ }^{17}$ Rate ratios were used to calculate the relative percent changes in alert acceptance. All analyses were performed using Stata/SE version 13 (Statacorp, College Station, Texas, United States).

\section{Results}

There were similar numbers of medication orders placed during 5 months before and after the intervention ( - Table 1). Medication orders generated from 1 to 18 alerts before the intervention, and from 1 to 21 alerts after the intervention. There was a $37.5 \%$ relative decrease in the percentage of medication orders generating alerts after the intervention, though only a $9.6 \%$ absolute decrease. There was a $39.6 \%$ relative increase in the percentage of orders erased (i.e., all alerts accepted) in response to alerts after the intervention but only a $2.1 \%$ absolute increase (-Table 1).

There was a $25.9 \%$ relative ( $4.3 \%$ absolute) decrease in the percent of medication orders generating a single alert after the intervention, and a $37.9 \%$ relative (2.2\% absolute) increase in the percent of single orders erased (i.e., alert accepted) in response to alerts after the intervention (-Table 1). Data regarding the patients, providers, and medications associated with the orders generating single alerts are shown in - Table 2 . There was a small but significant difference in the age of patients before and after the intervention. There were no other significant differences among patients, caregivers, or medications.

DDI alerts accounted for $47.9 \%$ of single alerts before the intervention, and $14.8 \%$ of single alerts after the intervention ( - Table 3), a $69.1 \%$ relative (33.1\% absolute) decrease. For our primary outcome, there was a statistically significant $85.7 \%$ relative increase in acceptance of DDI alerts after the intervention, though only a $1.8 \%$ absolute increase. Drug-allergy alerts accounted for $5.7 \%$ of single alerts before the intervention and $7.3 \%$ afterwards, a statistically significant $28.1 \%$ relative (1.6\% absolute) increase, and there was a $16.4 \%$ relative (3.5\% absolute) decrease in drug-allergy alert acceptance after the intervention. Relative adverse reaction alert acceptance increased by $21.7 \%$ (4.8\% absolute), however this change was not statistically significant, and there was no significant change in drug-duplicate alert acceptance before and after the intervention. When a regression analysis was performed the findings were essentially the same ( - Table 4 ).

\section{Discussion}

The elimination of intermediate DDI alerts resulted in a moderate decrease in the number of orders generating medication alerts, and a statistically significant increase in medication alert acceptance. However, overall alert acceptance remained extremely low. DDI alerts decreased a relative $69.1 \%$ and the increase in overall alert acceptance was almost exclusively due to a nearly $96 \%$ relative increase in DDI alert acceptance. However, the acceptance rate for DDI alerts remained extremely low, lower than the rate for other types

Table 1 Number of orders placed, number for which alerts were generated, and number erased (alert[s] accepted), and relative change, pre- and postintervention

\begin{tabular}{|c|c|c|c|c|}
\hline & $\begin{array}{l}\text { Preintervention } \\
n \text { (calculation and \%) }\end{array}$ & $\begin{array}{l}\text { Postintervention } \\
n \text { (calculation and \%) }\end{array}$ & $\begin{array}{l}\text { Relative change } \\
(95 \% \mathrm{Cl} \text { in \%) }\end{array}$ & $\begin{array}{l}\text { Absolute change } \\
(95 \% \mathrm{Cl} \text { in \%) }\end{array}$ \\
\hline All medication orders & 241,915 & 245,757 & - & - \\
\hline $\begin{array}{l}\text { Medication orders that } \\
\text { generated } \\
\text { one or more alert }\end{array}$ & $\begin{array}{l}61,923 \\
(61,923 / 241,915=25.6 \%)\end{array}$ & $\begin{array}{l}39,254 \\
(39,254 / 245,757=16 \%)\end{array}$ & $\begin{array}{l}-37.5 \\
(-38.4 \text { to }-36.8)\end{array}$ & $\begin{array}{l}-9.6 \\
(-9.4 \text { to }-9.9 \%)\end{array}$ \\
\hline $\begin{array}{l}\text { Medication orders erased in } \\
\text { response to one or more } \\
\text { alerts (i.e., alerts accepted) }\end{array}$ & $\begin{array}{l}3,249 \\
(3,249 / 61,923=5.3 \%)\end{array}$ & $\begin{array}{l}2,884 \\
(2,884 / 39,254=7.4 \%)\end{array}$ & $\begin{array}{l}39.6 \\
(33.2-47.2)\end{array}$ & $\begin{array}{l}2.1 \\
(1.8-2.4)\end{array}$ \\
\hline $\begin{array}{l}\text { Medication orders that } \\
\text { generated single alerts }\end{array}$ & $\begin{array}{l}40,139 \\
(40,139 / 241,915=16.6 \%)\end{array}$ & $\begin{array}{l}30,158 \\
(30,158 / 245,757=12.3 \%)\end{array}$ & $\begin{array}{l}-25.9 \\
(-25.9 \text { to }-27.1)\end{array}$ & $\begin{array}{l}-4.3 \\
(4.1-4.5)\end{array}$ \\
\hline $\begin{array}{l}\text { Medication orders erased in } \\
\text { response to single alerts } \\
\text { (i.e., alert accepted) }\end{array}$ & $\begin{array}{l}2,336 \\
(2,336 / 40,139=5.8 \%)\end{array}$ & $\begin{array}{l}2,424 \\
(2,424 / 30,158=8 \%)\end{array}$ & $\begin{array}{l}37.9 \\
(32.5-43.9)\end{array}$ & $\begin{array}{l}2.2 \\
(1.8-2.6)\end{array}$ \\
\hline
\end{tabular}


Table 2 Patient, provider, and medication features for medication orders generating single alerts, pre- and postintervention

\begin{tabular}{|c|c|c|c|}
\hline & Preintervention & Postintervention & $p$-Value \\
\hline $\begin{array}{l}\text { Patient } \\
\text { characteristics }\end{array}$ & $n=7,145$ & $n=6,356$ & \\
\hline Mean age (SD) & $55.0(20.0)$ & $56.0(19.8)$ & 0.0036 \\
\hline Male (\%) & 45.9 & 45.3 & 0.48 \\
\hline $\begin{array}{l}\text { Median LOS } \\
\text { (IQR, max) }\end{array}$ & $3.0(2-6,106.0)$ & $3.0(2-6,98.0)$ & 0.52 \\
\hline ICU patients (\%) & 6.8 & 7.3 & 0.26 \\
\hline Caregiver types & $n=986$ & $n=924$ & 0.83 \\
\hline Attendings $s^{\mathrm{a}}(\%)$ & 23 & $23^{c}$ & \\
\hline Residents (\%) & 31 & 33 & \\
\hline APPs (\%) & 13 & 13 & \\
\hline Nurses (\%) & 32 & 29 & \\
\hline $\begin{array}{l}\text { Other } \\
\text { caregivers }^{\mathrm{b}}(\%)\end{array}$ & 2 & 3 & \\
\hline $\begin{array}{l}\text { Medication } \\
\text { characteristics }\end{array}$ & $n=1,015$ & $n=1,006$ & \\
\hline Parenteral (\%) & 24.7 & 25.0 & 0.91 \\
\hline $\begin{array}{l}\text { ISMP high-alert } \\
\text { medications (\%) }\end{array}$ & 16.7 & 18.8 & 0.18 \\
\hline
\end{tabular}

Abbreviations: APP, advanced practice provider; ICU, intensive care unit; $I Q R$, interquartile range; ISMP, Institute for Safe Medication Practice; LOS, length of stay; SD, standard deviation.

${ }^{a}$ Attending category includes teaching attendings, hospitalists and fellows. ${ }^{b}$ Other Caregivers include medical students, respiratory therapists, and pharmacists.

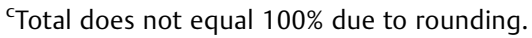

of medication alerts, even though the postintervention phase only included severe DDI alerts. Additionally, while we had hoped that significantly decreasing the DDI alert burden would increase attendance to other alerts, drug-duplicate alert acceptance remained unchanged, and drug-allergy alert acceptance unexpectedly decreased a small amount.

To the best of our knowledge, this is the first study to describe the findings associated with turning off an entire class of alerts. Many have suggested that alert fatigue causes decreased effec-
Table 4 Adjusted $^{\mathrm{a}}$ percentage change in alert acceptance preand postintervention

\begin{tabular}{|l|l|l|}
\hline $\begin{array}{l}\text { Alert } \\
\text { types }\end{array}$ & $\begin{array}{l}\text { Adjusted relative } \\
\text { change in alert } \\
\text { acceptance } \\
\text { (95\% Cl in \%) }\end{array}$ & $\begin{array}{l}\text { Adjusted absolute } \\
\text { change in alert } \\
\text { acceptance } \\
\text { (95\% Cl in \%) }\end{array}$ \\
\hline $\begin{array}{l}\text { Adverse } \\
\text { reaction }\end{array}$ & $\begin{array}{l}-0.5 \\
(-40.3 \text { to } 65.5)\end{array}$ & $\begin{array}{l}0.28 \\
(-10.1 \text { to } 10.7)\end{array}$ \\
\hline $\begin{array}{l}\text { Drug } \\
\text { allergy }\end{array}$ & $\begin{array}{l}-18.9 \\
(-29.0 \text { to }-7.3)\end{array}$ & $\begin{array}{l}-4.2 \\
(6.4 \text { to }-1.9 \%)\end{array}$ \\
\hline $\begin{array}{l}\text { Drug } \\
\text { duplicate }\end{array}$ & $0(-6.8$ to 7.1$)$ & $\begin{array}{l}0.03 \\
(-0.5 \text { to } 0.5)\end{array}$ \\
\hline $\begin{array}{l}\text { Drug-drug } \\
\text { interaction }\end{array}$ & $95.9(63.8-134.2)$ & $2.0(1.4-2.4)$ \\
\hline
\end{tabular}

Abbreviations: $\mathrm{Cl}$, confidence interval; ISMP, Institute for Safe Medication Practice.

${ }^{a}$ Adjusted for patient age, caregiver type, parenteral versus non-parenteral medication, and whether or not the medication is on the ISMP list of high-alert medications.

tiveness of clinical decision support in providers' order entry systems, and have called for greater specificity for medication alerts, particularly interruptive ones. ${ }^{6,13,21-25}$ Several studies have looked at the theoretical effects of decreasing alerts, ${ }^{26-28}$ yet only a few studies have looked at the effect of actually decreasing the alert burden in a computerized provider order entry (CPOE) system, as we did, and findings have been inconsistent. $^{29-33}$ One did not report alert acceptance rates, ${ }^{29}$ and two others found no change in the percent of alerts that were accepted. ${ }^{30,31}$ Others have found no association between alert burden and their acceptance rate. ${ }^{32,33}$

Medications alerts should not be turned off casually. 21,24 Decision-support experts recommend that institutions customize alert systems to eliminate clinically irrelevant alerts, with the hopes of decreasing alert fatigue and increasing the attention paid to more significant alerts. ${ }^{34-36}$ However, selectively analyzing alerts is labor intensive and may not be feasible for smaller institutions. ${ }^{35}$ Configuring the system to enable users to identify inappropriate alerts might help target

Table 3 Number of single alerts and percent accepted pre- and postintervention, and percent change in alert acceptance

\begin{tabular}{|c|c|c|c|c|c|c|}
\hline \multirow[b]{2}{*}{ Alert types } & \multicolumn{2}{|c|}{$\begin{array}{l}\text { Preintervention } \\
n=40,139\end{array}$} & \multicolumn{2}{|c|}{$\begin{array}{l}\text { Postintervention } \\
n=30,158\end{array}$} & \multirow[b]{2}{*}{$\begin{array}{l}\text { Relative change in alert } \\
\text { acceptance ( } 95 \% \mathrm{Cl} \text { in \%) }\end{array}$} & \multirow[b]{2}{*}{$\begin{array}{l}\text { Absolute change in } \\
\text { alert acceptance (\%) }\end{array}$} \\
\hline & $\begin{array}{l}\text { No. of } \\
\text { alerts (\%) }\end{array}$ & $\begin{array}{l}\text { No. of alerts } \\
\text { accepted (\%) }\end{array}$ & $\begin{array}{l}\text { No. of } \\
\text { alerts (\%) }\end{array}$ & $\begin{array}{l}\text { No. of alerts } \\
\text { accepted (\%) }\end{array}$ & & \\
\hline $\begin{array}{l}\text { Adverse } \\
\text { reaction }\end{array}$ & $\begin{array}{l}104 \\
(0.3)\end{array}$ & $\begin{array}{l}23 \\
(22.1)\end{array}$ & $\begin{array}{l}208^{a} \\
(0.7)\end{array}$ & $\begin{array}{l}56 \\
(26.9)\end{array}$ & $21.7(-25.1$ to 97.8$)$ & $+4.8(-5.4$ to 15.0$)$ \\
\hline Drug allergy & $\begin{array}{l}2,274 \\
(5.7)\end{array}$ & $\begin{array}{l}486 \\
(21.4)\end{array}$ & $\begin{array}{l}2,199^{a} \\
(7.3)\end{array}$ & $\begin{array}{l}394 \\
(17.9)\end{array}$ & $-16.4(-26.6$ to 4.3$)$ & $-3.5(-1.2$ to -5.8$)$ \\
\hline $\begin{array}{l}\text { Drug } \\
\text { duplicate }\end{array}$ & $\begin{array}{l}18,544 \\
(46.2)\end{array}$ & $\begin{array}{l}1,429 \\
(7.7)\end{array}$ & $\begin{array}{l}23,290^{\mathrm{a}} \\
(77.2)\end{array}$ & $\begin{array}{l}1,799 \\
(7.7)\end{array}$ & $0(-6.5$ to 7.4$)$ & $0(-0.5$ to 0.5$)$ \\
\hline $\begin{array}{l}\text { Drug-drug } \\
\text { interaction }\end{array}$ & $\begin{array}{l}19,217 \\
(47.9)\end{array}$ & $\begin{array}{l}398 \\
(2.1)\end{array}$ & $\begin{array}{l}4,461 \\
(14.8)\end{array}$ & $\begin{array}{l}175 \\
(3.9)\end{array}$ & $85.7(58.6-126.2)$ & $1.8(1.3-2.3)$ \\
\hline
\end{tabular}

${ }^{a}$ The number of single adverse reaction, drug-allergy and drug-duplicate alerts appear increased in the postintervention phase of the study because preintervention many of them would have been grouped with Intermediate severity DDI alerts, and therefore would not have been included in data looking only at single alerts in the preintervention phase. 
those worth removing. ${ }^{37}$ However, providers differ in their opinions of the value of alerts, ${ }^{38,39}$ their perceptions of which are important, ${ }^{26}$ and their rates of responses to them. ${ }^{40}$ In one study, there was no correlation between designated alert severity and the number of providers who thought an alert could be safely turned off. ${ }^{26}$ Alerts might prompt heightened monitoring for potential adverse events, even if they are overridden. Additionally, medication alert systems generally do not consider the effect of patient context and other nondrug contributions to medication-related adverse events. This was demonstrated in another study which showed that restricting alerts to obviously QT-prolonging drugs would not improve the positive predictive value of the remaining alerts, and would identify less than half of patients at risk for torsades de pointes. ${ }^{27}$ Institutions might also be concerned about the legal ramifications of turning alerts off. ${ }^{41}$ Broadly accepted recommendations are needed about which alerts are critical, rather than expecting every institution to independently assess the importance of every alert. ${ }^{21,42-44}$

The medication alert acceptance rate in this study, even after our intervention, was lower than the 11.5 to $26.7 \%$ rates, recently reported for inpatients. ${ }^{45,46}$ Most likely it would be necessary to change the way medication alerts appear and behave, in addition to decrease the alert burden to increase the acceptance rate in our system to that seen more typically. There is huge variation between EMRs in the appearance and capabilities of their decision support functionality. ${ }^{21,43,47,48}$ Ideally DDI alerts are displayed at the point when a medication order is first entered, and not when attempting to sign all orders in a session. ${ }^{21,49}$ Some studies have reported increased alert acceptance when critical alerts are displayed more intrusively than those that are less important. ${ }^{13,50,51} \mathrm{DDI}$ alerts should include clear identification of the interacting drug pair, the potential consequence, its seriousness, and recommended action, with easy access to the mechanism of interaction, patient contextual information, and available evidence regarding the interaction. ${ }^{21}$ However, many EMRs, like ours at the time of this study, do not incorporate these recommendations. Fortunately our institution moved to an EMR which satisfies many of them a year and a half after this study took place.

\section{Limitations}

Several limitations of our study should be considered. First, we were unable to distinguish "intermediate" and "severe" DDI alerts in the preintervention group, and therefore compared responses to both to just the remaining "severe" DDI alerts in the postintervention group. Intermediate DDI alerts are probably accepted at different rates than severe DDI alerts; for example, an intermediate DDI alert might be more likely than a severe DDI alert to be justifiably overridden while simultaneously prompting increased surveillance for adverse events. It is possible that we had compared only "severe" DDI alerts; we would have found no difference in that portion of the analysis. Second, we did not account for possible clustering around patients for whom multiple orders were placed or around providers with a higher alert burden, for whom alert acceptance might have been lower. Third, we used a pre-post study design that might not take into account other changes in the local environment or changes in the users themselves, particularly residents who could have occurred before and after the system change was made. Fourth, the DDI alert thresholds were defined by a proprietary commercial algorithm and we did not consider their validity, nor the appropriateness of the DDIs left in place; it is possible that we eliminated some clinically important DDIs and left in place certain low-value DDIs. Fifth, we did not measure patient outcomes, such as adverse drug events that are more important than acceptance rates when determining alerts effectiveness. ${ }^{21}$ Finally, the study was conducted at a single-medical center, and findings might be different in another setting or with another EMR.

\section{Conclusion}

Decreasing alert burden and increasing the significance of DDI alerts presented to providers resulted in a statistically significant increase in the acceptance rate for medication alerts overall, and for DDIs in particular. However, overall alert acceptance, and acceptance of DDI alerts, remained dismally low, and the rate of alert acceptance was unchanged for drugduplicate and decreased for drug-allergy alerts. Further study is needed to determine if alert acceptance would have been increased by modifying alert appearance or behavior, or by provider education, and to determine if interventions like ours will have an effect on alert fatigue and patient outcomes.

\section{Clinical Relevance Statement}

Clinical decision support can guide caregiver to make decision when placing orders; however, caregivers may be exposed to so many decision support alerts that they experience alert fatigue and hindering the effectiveness of the alerts. It is assumed, but not known for certain, that caregivers exposed to fewer alerts will be more likely to respond as desired to the remaining alerts. This study found that eliminating a class of DDI alerts was associated with a statistically significant increase in alert acceptance; however, overall alert acceptance remained very low.

\section{Multiple Choice Questions}

1. Which of the following approaches is the definitive method for reducing alert fatigue from medication alerts in computerized order entry systems?

a. Reducing the number of alerts to which caregivers are exposed.

b. Displaying alerts of higher significance more prominently than those of lower significance.

c. Customizing alerts according to patient or ordering provider characteristics.

d. None of the above.

Correct Answer: The correct answer is option d, none of the above. While each of these approaches intuitively seem like they would help to reduce alert fatigue from medication alerts, and some have been shown to increase 
alert acceptance, there is no single approach for reducing alert fatigue from medication alerts. Modifying medication alert systems is an unwieldy task, due to the number of alerts available by default in order entry systems, the complexities of the changes, and the fear of litigation should a change be made that is subsequently perceived to have "caused" an untoward event (never mind the risk associated with ignoring important alerts that are buried among numerous less relevant alerts). While findings from numerous manuscripts suggest that each of these approaches can be helpful, and institutions must continue to make a wholehearted effort to improve the situation for their users, there is as yet no "one right approach" for reducing alert fatigue.

2. National standards are needed for medication alerts because:

a. The HITECH Act mandated national standards for medication alerts as part of the 2009 economic stimulus package.

b. Litigation has been brought against institutions that have independently turned off medication alerts, when that action has been determined to have contributed to a patient safety event.

c. Determining which alerts are significant is a massive undertaking, not feasible for many smaller institutions.

d. Institutional and regional variations are of no significance when determining whether or not a medication alert is needed.

Correct Answer: The correct answer is option c. Determining which medication alerts are significant is a painstaking process, requiring multidisciplinary stakeholders to consider, for every possible alert, the severity of the situation for which the alert is generated, the knowledge base of most prescribers encountering the situation, the scenarios in which the alert is typically encountered, and the patients in whom it occurs. While some institutions might choose an approach similar to that we took, eliminating all alert of a particular class as a start, a more stepwise, cautious approach is generally advisable, given the importance of the consequences. This can be a laborious, month-long process, requiring many hours of time, and may be challenging for smaller institutions to take on. Institutional and regional variations are absolutely important when determining whether or not a medication alert is needed; however, broad national guidelines from a recognized body are still warranted, with an outline of those local factors to be considered when implementing each change.

To our knowledge, no litigation has ever been taken against an institution which has turned off certain medication alerts, because of a perception that a patient safety event has resulted; however, that is certainly a concern for those initiating these changes.

The HITECH Act promoted the adoption and meaningful use of health information technology; it did not include specific recommendations for which medication alerts to display or suppress from prescribers.

\section{Authors' Contributions}

All listed authors contributed substantially to the study conception and design or analysis and interpretation of data, drafting the article, or revising it critically for important intellectual content, and final approval of the version to be published. No one who fulfills these criteria has been excluded from authorship.

\section{Protection of Human and Animal Subjects}

The study was performed in compliance with the World Medical Association Declaration of Helsinki on Ethical Principles for Medical Research Involving Human Patients, and was reviewed by Johns Hopkins Institutional Review Board.

Funding

This publication was made possible by the Johns Hopkins Institute for Clinical and Translational Research (ICTR) which is funded in part by Grant Number UL1 TR 001079 from the National Center for Advancing Translational Sciences (NCATS) a component of the National Institutes of Health (NIH), and NIH Roadmap for Medical Research. Its contents are solely the responsibility of the authors and do not necessarily represent the official view of the Johns Hopkins ICTR, NCATS or NIH.

\section{Conflict of Interest}

None declared.

\section{Acknowledgments}

Particular thanks go to Scott Carey and Olga Sherman for assistance with data collection and to Nola Durkin for assistance with statistical analysis.

\section{References}

1 Shortliffe EH. Computer programs to support clinical decision making. JAMA 1987;258(01):61-66

2 Clinical decision support. Available at: https://www.ahrq.gov/ cpi/about/otherwebsites/clinical-decision-support/index.html. Accessed August 13, 2019

3 Bright TJ, Wong A, Dhurjati R, et al. Effect of clinical decisionsupport systems: a systematic review. Ann Intern Med 2012;157 (01):29-43

4 Nuckols TK, Smith-Spangler C, Morton SC, et al. The effectiveness of computerized order entry at reducing preventable adverse drug events and medication errors in hospital settings: a systematic review and meta-analysis. Syst Rev 2014;3:56

5 Murphy DR, Reis B, Sittig DF, Singh H. Notifications received by primary care practitioners in electronic health records: a taxonomy and time analysis. Am J Med 2012;125(02):209.e1-209.e7

6 Weingart SN, Simchowitz B, Shiman L, et al. Clinicians' assessments of electronic medication safety alerts in ambulatory care. Arch Intern Med 2009;169(17):1627-1632

7 Glassman PA, Simon B, Belperio P, Lanto A. Improving recognition of drug interactions: benefits and barriers to using automated drug alerts. Med Care 2002;40(12):1161-1171

8 Campbell EM, Sittig DF, Ash JS, Guappone KP, Dykstra RH. Types of unintended consequences related to computerized provider order entry. J Am Med Inform Assoc 2006;13(05):547-556

9 Ranji SR, Rennke S, Wachter RM. Computerised provider order entry combined with clinical decision support systems to improve medication safety: a narrative review. BMJ Qual Saf 2014;23(09):773-780

10 Kane-Gill SL, O'Connor MF, Rothschild JM, et al. Technologic distractions (part 1): Summary of approaches to manage alert 
quantity with intent to reduce alert fatigue and suggestions for alert fatigue metrics. Crit Care Med 2017;45(09):1481-1488

11 van der Sijs H, Aarts J, Vulto A, Berg M. Overriding of drug safety alerts in computerized physician order entry. J Am Med Inform Assoc 2006;13(02):138-147

12 Isaac T, Weissman JS, Davis RB, et al. Overrides of medication alerts in ambulatory care. Arch Intern Med 2009;169(03):305-311

13 Nanji KC, Slight SP, Seger DL, et al. Overrides of medication-related clinical decision support alerts in outpatients. J Am Med Inform Assoc 2014;21(03):487-491

14 Carspecken CW, Sharek PJ, Longhurst C, Pageler NM. A clinical case of electronic health record drug alert fatigue: consequences for patient outcome. Pediatrics 2013;131(06):e1970-e1973

15 Wachter R. The Digital Doctor: Hope, Hype, and Harm at the Dawn of Medicine's Computer Age. 1st ed. New York, NY: McGraw Hill Education; 2015

16 Wong A, Rehr C, Seger DL, et al. Evaluation of harm associated with high dose-range clinical decision support overrides in the intensive care unit. Drug Saf 2019;42(04):573-579

17 Knight AM, Falade O, Maygers J, Sevransky JE. Factors associated with medication warning acceptance for hospitalized adults. J Hosp Med 2015;10(01):19-25

18 Thiemann DR. Chair, Johns Hopkins Hospital Clinical Decision Support Committee. Personal communication, 10/14/2013.

19 McAlduff J, VP-CMIO, MedStar Health, Columbia, Maryland. Email communication, $11 / 27-28 / 13$

20 Institute for Safe Medication Practice. High-alert medications in acute care setting. Available at: https://www.ismp.org/recommendations/high-alert-medications-acute-list. Accessed August 5, 2019

21 Payne TH, Hines LE, Chan RC, et al. Recommendations to improve the usability of drug-drug interaction clinical decision support alerts. J Am Med Inform Assoc 2015;22(06):1243-1250

22 Phansalkar S, van der Sijs H, Tucker AD, et al. Drug-drug interactions that should be non-interruptive in order to reduce alert fatigue in electronic health records. J Am Med Inform Assoc 2013; 20(03):489-493

23 Bates DW. CPOE and clinical decision support in hospitals: getting the benefits: comment on "Unintended effects of a computerized physician order entry nearly hard-stop alert to prevent a drug interaction". Arch Intern Med 2010;170(17):1583-1584

24 Phansalkar S, Edworthy J, Hellier E, et al. A review of human factors principles for the design and implementation of medication safety alerts in clinical information systems. J Am Med Inform Assoc 2010;17(05):493-501

25 Classen DC, Phansalkar S, Bates DW. Critical drug-drug interactions for use in electronic health records systems with computerized physician order entry: review of leading approaches. J Patient Saf 2011;7(02):61-65

26 van der Sijs H, Aarts J, van Gelder T, Berg M, Vulto A. Turning off frequently overridden drug alerts: limited opportunities for doing it safely. J Am Med Inform Assoc 2008;15(04):439-448

27 van der Sijs H, Kowlesar R, Aarts J, Berg M, Vulto A, van Gelder T. Unintended consequences of reducing QT-alert overload in a computerized physician order entry system. Eur J Clin Pharmacol 2009;65(09):919-925

28 Lee EK, Mejia AF, Senior T, Jose J. Improving patient safety through medical alert management: An automated decision tool to reduce alert fatigue. AMIA Annu Symp Proc 2010;2010:417-421

29 Resetar E, Reichley RM, Noirot LA, Doherty JA, Dunagan WC, Bailey TC. Strategies for reducing nuisance alerts in a dose checking application. AMIA Annu Symp Proc 2005:624-628

30 Beccaro MA, Villanueva R, Knudson KM, Harvey EM, Langle JM, Paul $W$. Decision support alerts for medication ordering in a computerized provider order entry (CPOE) system: A systematic approach to decrease alerts. Appl Clin Inform 2010;1(03):346-362

31 Schreiber R, Gregoire JA, Shaha JE, Shaha SH. Think time: a novel approach to analysis of clinicians' behavior after reduction of drug-drug interaction alerts. Int J Med Inform 2017;97:59-67
32 Bryant AD, Fletcher GS, Payne TH. Drug interaction alert override rates in the Meaningful Use era: no evidence of progress. Appl Clin Inform 2014;5(03):802-813

33 Dexheimer JW, Kirkendall ES, Kouril M, et al. The effects of medication alerts on prescriber response in a pediatric hospital. Appl Clin Inform 2017;8(02):491-501

34 Schiff GD, Hickman TT, Volk LA, Bates DW, Wright A. Computerised prescribing for safer medication ordering: still a work in progress. BMJ Qual Saf 2016;25(05):315-319

35 Wright A, Sittig DF, Ash JS, et al. Governance for clinical decision support: case studies and recommended practices from leading institutions. J Am Med Inform Assoc 2011;18(02):187194

36 Kawamanto K, Flynn MC, Kukhareva P, et al. A pragmatic guide to establishing clinical decision support governance and addressing decision support fatigue: A case study. AMIA Annu Symp Proc 2018;2018:624-633

37 Rehr CA, Wong A, Seger DL, Bates DW. Determining inappropriate medication alerts from "inaccurate warning" overrides in the intensive care unit. Appl Clin Inform 2018;9(02):268-274

38 Ko Y, Abarca J, Malone DC, et al. Practitioners' views on computerized drug-drug interaction alerts in the VA system. J Am Med Inform Assoc 2007;14(01):56-64

39 Spina JR, Glassman PA, Simon B, et al. Potential safety gaps in order entry and automated drug alerts: a nationwide survey of VA physician self-reported practices with computerized order entry. Med Care 2011;49(10):904-910

40 Beeler PE, Orav EJ, Seger DL, Dykes PC, Bates DW. Provider variation in responses to warnings: do the same providers run stop signs repeatedly? J Am Med Inform Assoc 2016;23(e1): e93-e98

41 Kesselheim AS, Cresswell K, Phansalkar S, Bates DW, Sheikh A. Clinical decision support systems could be modified to reduce 'alert fatigue' while still minimizing the risk of litigation. Health Aff (Millwood) 2011;30(12):2310-2317

42 Phansalkar S, Desai AA, Bell D, et al. High-priority drug-drug interactions for use in electronic health records. J Am Med Inform Assoc 2012;19(05):735-743

43 McEvoy DS, Sittig DF, Hickman TT, et al. Variation in highpriority drug-drug interaction alerts across institutions and electronic health records. J Am Med Inform Assoc 2017;24 (02):331-338

44 Tilson H, Hines LE, McEvoy G, et al. Recommendations for selecting drug-drug interactions for clinical decision support. Am J Health Syst Pharm 2016;73(08):576-585

45 Nanji KC, Seger DL, Slight SP, et al. Medication-related clinical decision support alert overrides in inpatients. J Am Med Inform Assoc 2018;25(05):476-481

46 Wong A, Amato MG, Seger DL, et al. Prospective evaluation of medication-related clinical decision support over-rides in the intensive care unit. BMJ Qual Saf 2018;27(09):718-724

47 Phansalkar S, Zachariah M, Seidling HM, Mendes C, Volk L, Bates DW. Evaluation of medication alerts in electronic health records for compliance with human factors principles. J Am Med Inform Assoc 2014;21(e2):e332-e340

48 Wong A, Amato MG, Seger DL, et al. Evaluation of medicationrelated clinical decision support alert overrides in the intensive care unit. J Crit Care 2017;39:156-161

49 Coleman JJ, van der Sijs H, Haefeli WE, et al. On the alert: future priorities for alerts in clinical decision support for computerized physician order entry identified from a European workshop. BMC Med Inform Decis Mak 2013;13:111

50 Paterno MD, Maviglia SM, Gorman PN, et al. Tiering drug-drug interaction alerts by severity increases compliance rates. J Am Med Inform Assoc 2009;16(01):40-46

51 Shah NR, Seger AC, Seger DL, et al. Improving acceptance of computerized prescribing alerts in ambulatory care. J Am Med Inform Assoc 2006;13(01):5-11 